\title{
Cerebrovascular Accident Clinical Features, Clues for Diagnosis in the Acute Care Settings
}

\author{
Behzad Saberi* \\ Medical Research, Esfahan, Iran \\ *Corresponding author: Behzad Saberi, MD, Medical Research, Esfahan, Iran
}

\section{Mini Review}

There are common abnormalities which can be seen due to occlusion in the anterior or posterior circulation of the brain in the Cerebrovascular accident which can be helpful to localize the lesion at the bedside Aphasia, Amaurosis fugax, Hemisensory loss, Hemianopic visual loss and Hemiparesis are common abnormalities which can be seen in the occlusion of the anterior circulation which would be the territory of the carotid and comprise about 80 percent of the cases Hemianopic visual loss, Syncope, Tetra paresis, Transient global amnesia, Ataxia, Diplopia, Dysarthria, Chocking, Hemisensory loss, Vertigo and Vomiting are common abnormalities which can be seen in the occlusion of the posterior circulation which would be the territory of the vertebrobasilar and comprise about 20 percent of the cases. In the anterior circulation, Hemianopia visual loss can be seen in the infarction of the visual pathway. Infarction of the thalamocortical fiber or the ventral thalamic infarction can cause Hemisensory loss. Embolism of the central artery to the retina can cause Amaurosis fugax. Aphasia can be seen because of the infarction of the Broca's area or the central speech area. Infarction of the pyramidal tract at the posterior limb of the internal capsule can cause Hemiparesis [1-3].

In the posterior circulation, Infarction of the cerebellum and its connection can cause Ataxia. Occipital cortex or visual path infarction results in Hemianopic visual loss. Tetra paresis can be seen in the infarction of the great decussation of the pyramid. Vestibulocochlear nerve infarction results in vertigo and vomiting. Infarction of the glossopharyngeal, vagus, accessory and hypoglossal nerves causes Dysarthria. Transient global amnesia can be the result of the parietotemporal cortex infarction. Oculomotor, trochlear and trigeminal nerves nuclei or medial longitudinal fasciculus infarction causes Diplopia. Hemisensory loss is the result of the spinothalamic tract infarction. Infarction of the respiratory center causes Chocking. Syncope can be seen by the infarction of the ascending reticular system and the pons. It is important for the clinicians to have knowledge about the clinical features of the Cerebrovascular accident, to better diagnose and make proper decisions to treat the relevant pathologies specifically in the acute care settings $[4,5]$.

\section{References}

1. Bamford J, Sandercock P, Dennis M, Burn J, Warlow C (1991) Classification and natural history of clinically identifiable subtypes of cerebral infarction. Lancet 337(8756): 1521-1526.

2. Bamford JM (2000) The role of the clinical examination in the subclassification of stroke. Cerebrovasc Dis 10 Suppl 4(4): 2-4.

3. Louis R Caplan (2009) Caplan's Stroke: A Clinical Approach. Elsevier Health Sciences. ISBN 978-1-4160-4721-6.

4. Amarenco P, Bogousslavsky J, Caplan LR, Donnan GA, Hennerici MG (2009) Classification of Stroke Subtypes. Cerebrovascular Diseases 27 (5): 493-501.

5. Ropper, Allan H, Adams, Raymond Delacy, Brown, et al. (2005) Adams and Victor's principles of neurology. New York, USA McGraw-Hill Medical Pub Division pp. 686-704. 
(C) (i) This work is licensed under Creative

To Submit Your Article Click Here: Submit Article

DOI: $10.32474 /$ GJAPM.2020.03.000169

$\begin{gathered}\text { Global Journal of Anesthesia } \\
\text { \& Pain Medicine }\end{gathered} \mid$\begin{tabular}{l} 
Assets of Publishing with us \\
- Global archiving of articles \\
- Immediate, unrestricted online access \\
- Rigorous Peer Review Process \\
\hline Anesthesia \& Pain Medicine
\end{tabular}

